Rev. Bras. Saúde Prod. Anim., Salvador, v.14, n.3, p.587-598 jul./set., 2013 http://www.rbspa.ufba.br ISSN 15199940

\title{
Efeito da adubação orgânica e altura de resíduo sobre a produção de fitomassa do capim-buffel
}

\author{
Effect of organic fertilization and stubble height on the production biomass of buffel grass
}

FREITAS, Poliane Meire Dias de ${ }^{1 *}$; SANTOS, Edson Mauro ${ }^{2}$; RAMOS, João Paulo de Farias $^{3}$; BEZERRA, Higor Fábio Carvalho ${ }^{4}$; SILVA, Divan Soares ${ }^{2}$; SILVA, Ivandro de França da ${ }^{2}$; PERAZZO, Alexandre Fernandes ${ }^{5}$; PEREIRA, Gildênia Araújo ${ }^{3}$

\footnotetext{
${ }^{1}$ Universidade Federal da Bahia, Escola de Medicina Veterinária e Zootecnia, Programa de PósGraduação em Ciência Animal nos Trópicos, Salvador, Bahia, Brasil.

${ }^{2}$ Universidade Federal da Paraíba, Centro de Ciências Agrárias, Departamento de Zootecnia, Areia, Brasil.

${ }^{3}$ Universidade Federal da Paraíba, Centro de Ciências Agrárias, Areia, Paraíba, Brasil.

${ }^{4}$ Universidade Federal da Paraíba, Centro de Ciências Agrárias, Programa de Pós-Graduação, Areia, Paraíba, Brasil.

${ }^{5}$ Universidade Federal da Bahia, Escola de Medicina Veterinária e Zootecnia, Programa de PósGraduação em Zootecnia, Salvador, Bahia, Brasil.

*Endereço para correspondência: polianemeire@hotmail.com
}

\section{RESUMO}

Objetivou-se avaliar o efeito de níveis de adubação orgânica utilizando esterco caprino e duas alturas de resíduo, sobre a produção de fitomassa do capim-buffel. Utilizou-se parcelas subdivididas, no delineamento experimental de blocos completos ao acaso, com cinco repetições. As parcelas consistiram de doses de esterco caprino $(0 ; 5 ; 10$; 15 e 20t/ha), e as subparcelas consistiram em duas alturas de resíduo $(10$ e $20 \mathrm{~cm})$. Para produção de matéria verde houve efeito de ciclo, como também houve interação entre altura de resíduo e adubação. Com relação à produção de matéria seca, houve efeito de altura de resíduo, de adubação e da época de corte, sendo que verificou diferenças entre alturas somente quando o capim recebeu doses 10 e 20t/ha de adubo orgânico. O acúmulo total de colmo apresentou incremento de forma linear, com a utilização das doses de adubação quando o capim foi colhido na altura de $10 \mathrm{~cm}$, não havendo ajustes de modelos quando o mesmo foi colhido a $20 \mathrm{~cm}$. Foi observado um aumento linear do acúmulo líquido na altura de $10 \mathrm{~cm}$ conforme o acréscimo das doses de adubo. A adubação orgânica eleva a produção de fitomassa do capim buffel quando é cortado na altura de resíduo de $10 \mathrm{~cm}$.

Palavras-chave: acúmulo de biomassa, altura de corte, Cenchrus ciliaris, esterco caprino, Semiárido

\section{SUMMARY}

The objective of this work was to evaluate effect of organic fertilization levels using goat manure and two stubble heights, on the biomass production of buffel grass. We used a split plot in a randomized complete block design with five replications. The plots consisted of doses of goat manure $(0 ; 5 ; 10,15$ and $20 \mathrm{t} / \mathrm{ha})$ and the subplots consisted of two heights of residue (10 and $20 \mathrm{~cm})$. In the production of green matter of buffel grass, had effect, as well as an interaction effect between stubble heights and fertilization. With respect to dry matter production of buffel grass, there was also an effect of stubble heights, fertilizer and cut time, and there were differences between heights only when the grass to received 10 and $20 \mathrm{t} / \mathrm{ha}$ doses organic fertilizer. The total accumulation of stem showed a linear increase, using doses of fertilizer when the grass was harvested at the height of $10 \mathrm{~cm}$, without adjustments even when the templates were harvested at $20 \mathrm{~cm}$. There was a linear increase accumulation of liquid at the height of $10 \mathrm{~cm}$ as the higher doses of fertilizer. The organic fertilization increases the biomass production of buffel grass is cut when the height of $10 \mathrm{~cm}$ residue.

Keywords: accumulation of biomass, Cenchrus ciliaris, cult height, goat manure, Semiárido 


\section{INTRODUÇÃO}

A região do Semiárido brasileiro caracteriza-se por uma distribuição irregular de chuvas, concentradas num curto período de meses, que muitas vezes ocorre de forma repentina $\mathrm{e}$ torrencial, seguidas de um grande período de escassez, além de apresentar temperaturas elevadas durante maior parte do ano. Essas características climáticas são fatores determinantes na produção agropecuária da região, sendo necessária a utilização de forrageiras adaptadas ao clima para obtenção de uma maior produção de volumosos.

O capim-buffel (Cenchrus ciliaris) vem sendo cultivado em todo semiárido, é uma gramínea de relevância na produção animal por apresentar resistência à seca, ao pastejo intensivo e grande capacidade de rebrota, sendo muito usado como feno devido às desejáveis características: folhas finas e boa relação folha/colmo. Entretanto, não há conhecimento sobre o manejo correto de colheita e utilização de resíduos orgânicos para melhoria da produtividade do capim-buffel no semiárido.

Os solos das regiões semiáridas são deficientes em alguns nutrientes, bem com matéria orgânica, e por consequência, a produtividade sem adubação é muito limitada. A utilização de esterco é uma opção viável de suprimento de nutrientes para o solo, principalmente de $\mathrm{N}$, além de disponibilizar grande quantidade de matéria orgânica, em especial nas áreas de agricultura familiar. Os fertilizantes comerciais são pouco utilizados nessa região, devido o baixo poder aquisitivo dos produtores, à dificuldade de acesso ao crédito rural e à elevada variabilidade na precipitação pluvial. Recentemente, tentou-se combinar a aplicação de esterco com a adubação verde, mas esta forma de manejo não tem sido amplamente adotada pelos agricultores (SILVA et al., 2007; MENEZES \& SALCEDO, 2007).

Os resíduos orgânicos não utilizados têm papel importante no acréscimo da produção de forragem, por fornecer nutrientes, melhorando os atributos físicos, químicos e biológicos do solo. Segundo Melo et al. (2009) mesmo com tantos benefícios acarretados com o uso do esterco caprino para produção forrageira, a utilização do mesmo na região do semiárido brasileiro é bastante limitada.

A quantidade de carboidratos de reserva e tecido fotossintético remanescentes da planta influencia a capacidade de rebrota por afetar diretamente a fotossíntese, sendo importante para o manejo de gramíneas, o controle da altura de resíduo após o corte ou pastejo (SILVA \& NASCIMENTO JUNIOR, 2007), buscando o aumento da massa forrageira ao final do ciclo.

Objetivou-se com esta pesquisa avaliar a produção e o acúmulo de fitomassa do capim-buffel sob doses de adubação orgânica e alturas de resíduos.

\section{MATERIAL E MÉTODOS}

A pesquisa foi conduzida na Estação Experimental Pendência, localizada no município de Soledade-PB, pertencente à Empresa Estadual de Pesquisa Agropecuária da Paraíba S.A. (EMEPAPB), situada na Mesorregião do Agreste paraibano, microrregião do Curimataú Ocidental, tendo como coordenadas geográficas $7^{\circ} 03^{\prime} 30^{\prime}$ "de latitude Sul e $36^{\circ} 21^{\prime} 47^{\prime \prime}$ de longitude Oeste..

A área total utilizada foi dividida em 20 parcelas de $18 \mathrm{~m}^{2}(3,0 \times 6,0 \mathrm{~m})$ cada, com linhas de bordadura de $2 \mathrm{~m}$ entre 
parcelas e entre blocos. Utilizou-se o esquema de parcelas subdivididas, no delineamento experimental de blocos completos ao acaso, com cinco repetições. As parcelas consistiram das doses de esterco caprino $(0 ; 5 ; 10 ; 15$ e $20 \mathrm{t} / \mathrm{ha})$ e as subparcelas de duas alturas de resíduo (10 e $20 \mathrm{~cm})$.

Foi utilizada uma pastagem de capimbuffel cv. Biloela, já implantada, em solo classificado como Luvissolo, com textura média e baixo teor de matéria orgânica. $\mathrm{O}$ solo apresentou os seguintes atributos químicos: $\mathrm{pH}$ em água $=6,7 ; \mathrm{P}$ disponível $=27,1, \mathrm{~K}=$ $142\left(\mathrm{mg} / \mathrm{dm}^{3}\right) ; \mathrm{Ca}=5,45, \mathrm{Mg}=1,1 ; \mathrm{Al}$ $=0,0$, Soma de bases $=7,26, \mathrm{H}+\mathrm{AL}=$ $1,49, \quad$ CTC $=8,75 \quad\left(\mathrm{cmol}_{\mathrm{c}} / \mathrm{dm}^{3}\right)$;
Saturação por bases $=82,97 \%$ e matéria orgânica $(\mathrm{MO})=7,58 \mathrm{~g} / \mathrm{kg}$.

O esterco caprino possuía os seguintes atributos químicos: $\mathrm{pH}$ em água $=9,29 ; \mathrm{P}$ disponível $=1065, \mathrm{~K}=3883\left(\mathrm{mg} / \mathrm{dm}^{3}\right)$; $\mathrm{Ca}=4,55, \mathrm{Mg}=3,8 ; \mathrm{Na}=9,63$ $\left(\mathrm{cmol}_{\mathcal{C}} / \mathrm{dm}^{3}\right)$; Matéria orgânica = $110,60 \mathrm{~g} / \mathrm{kg}$. A adubação orgânica foi realizada no início do experimento, momento em que se cortou o pasto de cada subparcela na altura correspondente. A temperatura do ar média mensal, durante o período experimental, variou de $18^{\circ} \mathrm{C}$ a $25^{\circ} \mathrm{C}$ pela manhã $(7 \mathrm{~h})$ e de $26,2^{\circ} \mathrm{C}$ a $34,7^{\circ} \mathrm{C}$ à tarde $(14 \mathrm{~h}) . \quad \mathrm{A}$ umidade relativa do ar oscilou entre $96 \%$ pela manhã e $52 \%$ à tarde, nos mesmos horários (Tabela 1).

Tabela 1. Media mensal de temperatura e umidade relativa do ar referente aos meses de janeiro à agosto do ano de 2010 na Estação Experimental Pendência, Soledade-PB

\begin{tabular}{lcccccc}
\hline \multirow{2}{*}{ Mês } & \multicolumn{2}{c}{$\begin{array}{c}\text { Temperatura }{ }^{\circ} \mathrm{C} \\
\text { Horário: } 7: 00\end{array}$} & \multicolumn{2}{c}{ Temperatura ${ }^{\circ} \mathrm{C}$} & \multicolumn{2}{c}{ Umidade } \\
& Merário: $14: 00$ & \multicolumn{2}{c}{ Relativa $(\%)$} \\
\cline { 2 - 7 } & Mínima & Máxima & Mínima & Máxima & Manhã & Tarde \\
\hline Janeiro & 21,5 & 23,9 & 27,3 & 29,7 & 92 & 65 \\
Fevereiro & 22,5 & 24,7 & 30,1 & 33,4 & 92 & 56 \\
Março & 22,3 & 25,0 & 31,8 & 34,7 & 88 & 52 \\
Abril & 22,7 & 25,0 & 30,2 & 32,1 & 96 & 70 \\
Maio & 21,8 & 23,8 & 28,0 & 30,3 & 91 & 65 \\
Junho & 19,0 & 22,2 & 26,2 & 28,1 & 91 & 68 \\
Julho & 18,0 & 21,5 & 26,5 & 29,3 & 95 & 69 \\
Agosto & 22,0 & 24,5 & 30,5 & 32,0 & 93 & 66 \\
\hline
\end{tabular}

A precipitação pluvial total durante $\mathrm{o}$ período experimental (Figura 1) que compreendeu 200 dias, foi de 401,1mm, sendo que $10,57 \%$ do acumulado ocorreram em fevereiro, $29,92 \%$ em março, 7,9\% em abril, 27,65\% em maio, $19,35 \%$ em junho, $0,87 \%$ em julho e $3,74 \%$ em agosto.

$\mathrm{O}$ experimento compreendeu um período de 200 dias, dividido em quatro ciclos, três com 40 dias e o ultimo com 80 dias de duração. A razão para a maior duração do último ciclo se deveu ao fato da gramínea ter paralisado o seu crescimento após o terceiro ciclo, não havendo massa de forragem acima da altura de resíduo pré-estabelecida.

Toda forragem presente em cada subparcela foi cortada conforme a altura de resíduo e pesada para estimar a produção de matéria verde por área; dessa massa de forragem uma porção de aproximadamente $300 \mathrm{~g}$ foi pesada e seca em estufa de circulação forçada de 
ar a $65^{\circ} \mathrm{C}$ até atingir peso constante, objetivando-se determinar a quantidade de matéria seca (MS) do pasto. Os valores de massa de forragem foram convertidos para massa em um hectare, e a produção de matéria seca por hectare foi obtida pelo produto entre produção de matéria verde por hectare e teor de matéria seca do capim.

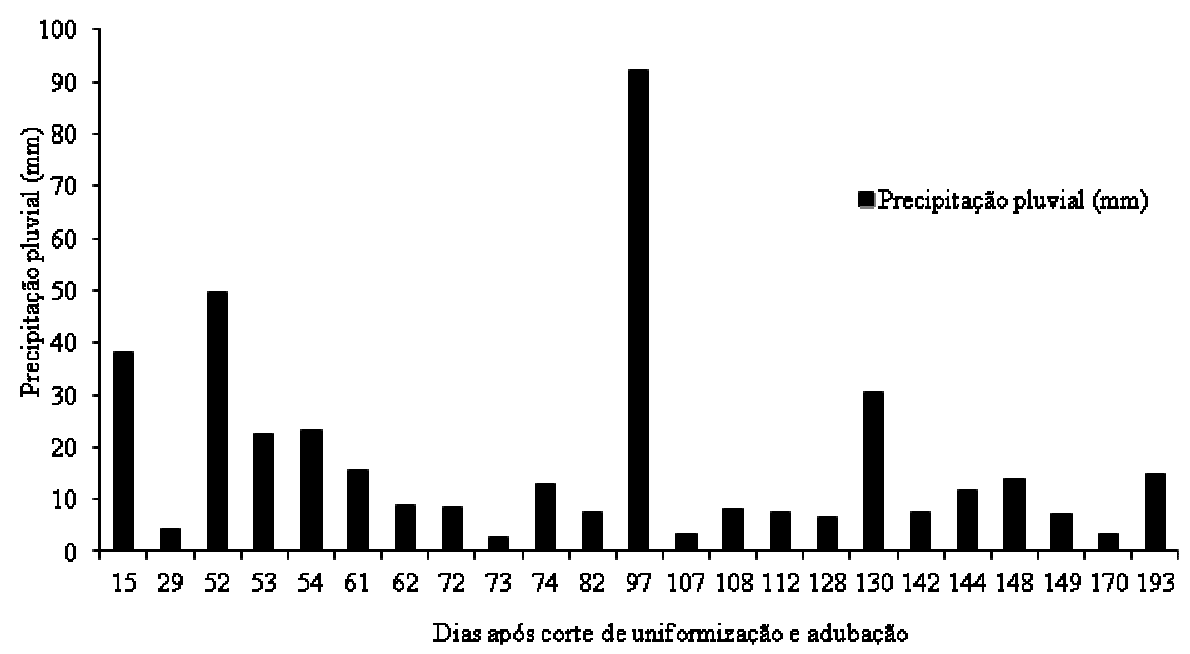

Figura 1. Distribuição da precipitação diária ocorrida entre o final de janeiro e início de agosto de 2010, na Estação Experimental Pendência, Soledade-PB

Para determinar o acúmulo de lâmina, colmo e material morto, foram colhidas amostras representativas de forragem acima da altura de corte estabelecida. As amostras de forragem foram separadas manualmente nas frações lâmina foliares, colmo (colmo + bainhas foliares) e material morto, as quais foram pesadas e secas em estufa para determinação dos teores de matéria seca (MS). O total de lâminas foliares, colmo e material morto por subparcela foi obtido pelo produto entre as proporções desse constituinte e o total de forragem, colhido acima da altura de resíduo préestabelecida, sendo posteriormente convertida em produção por hectare. $\mathrm{O}$ acúmulo líquido foi obtido pela diferença entre o acúmulo total e o acúmulo de material morto. $\mathrm{O}$ acúmulo diário foi obtido pelo quociente entre acúmulo total e a duração do ciclo, em dias.

Os dados foram submetidos à análise de variância. Para avaliação do efeito das alturas de corte, as médias foram comparadas pelo teste de Tukey, adotando-se um nível de significância de 5\%. Para avaliação do efeito da adubação, os dados foram submetidos à análise de regressão, adotando-se como critério para escolha dos modelos, a significância dos parâmetros de regressão pelo teste $\mathrm{t}$ de Student $(\mathrm{P}<0,05)$, bem como a coerência biológica das regressões. Para avaliação do efeito de ciclos de corte, as medidas foram repetidas no tempo e quando significativo o efeito, as médias foram comparadas pelo teste de Tukey $(\mathrm{P}<0,05)$. Os dados foram analisados utilizando-se o programa SISVAR (FERREIRA, 2008). 


\section{RESULTADOS E DISCUSSÃO}

Conforme a analise de variância das alturas de resíduo em relação à produção de matéria verde do capim- buffel, houve efeito $(\mathrm{P}<0,05)$ de adubação e de ciclo (Figura 2). Não houve efeito $(\mathrm{P}>0,05)$ de altura de resíduo, como também não houve interação entre altura de resíduo e adubação.
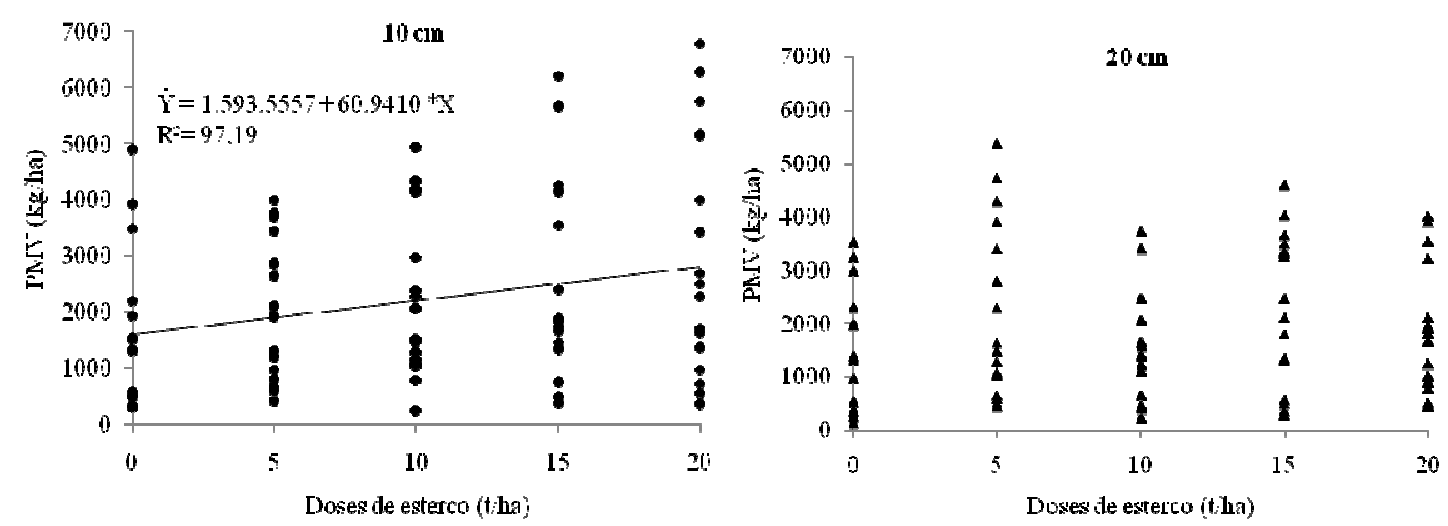

Figura 2. Valores médios da produção de matéria verde (PMV) do capim-buffel em função de doses de esterco e altura de resíduo

Conforme observado na Figura 2, o efeito de adubação somente foi observado quando o capim foi cortado a uma altura de $10 \mathrm{~cm}$, havendo aumento linear $(\mathrm{P}<0,05)$ na produção de fitomassa verde com elevação das doses de esterco caprino, porém em $20 \mathrm{~cm}$ não houve ajustes dos modelos de regressão, observando-se uma média geral de $1.938,23 \mathrm{~kg} / \mathrm{ha}$. Este resultado evidencia que o capim-buffel possui resistência ao corte mais rente, demonstrando que com a disponibilidade de nutrientes houve um aumento na velocidade e eficiência da rebrotação.

Em um estudo feito por Marcelino et al. (2006) avaliando a influência de intensidades $(10$ e $20 \mathrm{~cm})$ e frequências de desfolhação nas características morfogênicas e estruturais, no perfilhamento e na produção de forragem de Brachiaria brizantha cv. Marandu verificaram que cortes mais intensos e frequentes proporcionaram maior renovação dos tecidos, por proporcionar maiores taxas de aparecimento foliar, aumentar a densidade populacional de perfilho e prevenir o intenso alongamento de colmo, além disto, folhas novas são mais fotossinteticamente ativas que folhas maduras, desta forma, proporcionando um maior eficiência na produção de forragem quando supridas às exigências nutricionais das plantas, fato este, semelhantemente ao observado nesse estudo.

Com relação à produção de matéria seca do capim-buffel, houve efeito $(\mathrm{P}<0,05)$ de altura de resíduo e de adubação, sendo que para altura de resíduo a $10 \mathrm{~cm}$ foi observado ajuste de modelo linear crescente, apresentando a maior produtividade com a emprego de $20 \mathrm{t} / \mathrm{h}$ de esterco, com cerca de $806 \mathrm{~kg} / \mathrm{ha}$ de MS. Para a altura de resíduo a $20 \mathrm{~cm}$ não houve ajuste de modelo $(\mathrm{P}<0,05)$, apresentando maior produtividade com a utilização da dose de esterco de $15 \mathrm{t}$ /ha (Tabela 2). 

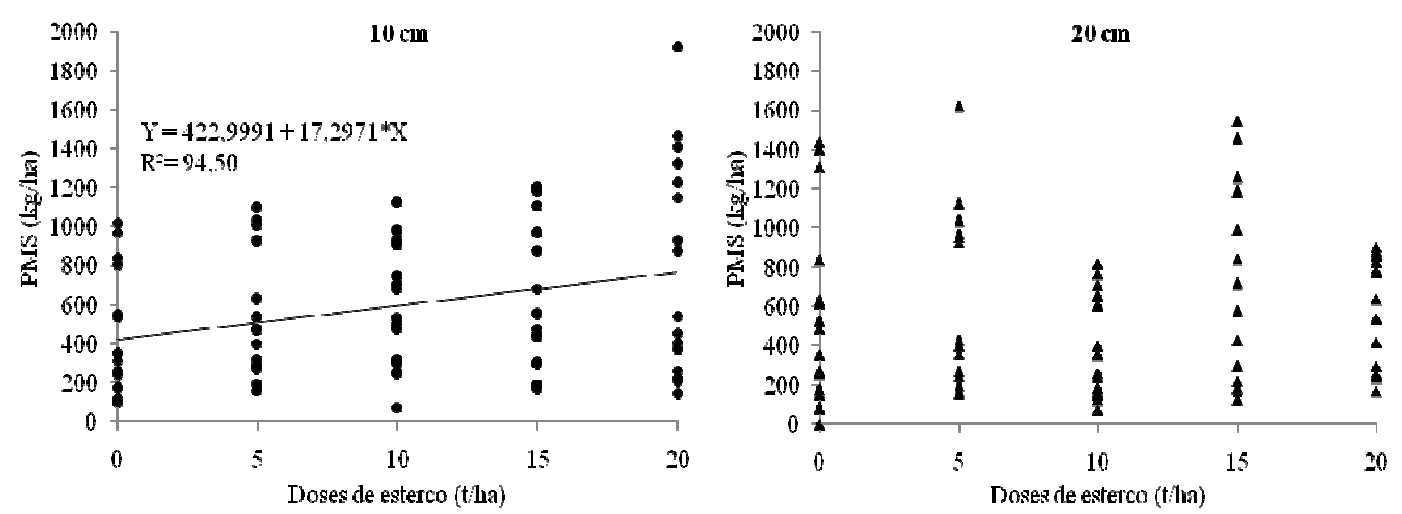

Figura 3. Valores médios da produção de matéria seca (PMS) do capim-buffel em função de doses de esterco e altura de resíduo

Nagano (2011) em experimento avaliando o efeito de duas alturas de corte $(20$ e $40 \mathrm{~cm})$ e diferentes doses de adubo nitrogenado sobre o capimtanzânia observaram que a maior produção de matéria seca não foi alcançada pelas maiores doses de nitrogênio, porém teve a maior produção de matéria seca quando cortada a $20 \mathrm{~cm}$, corroborando com o resultado observado nesse estudo quando a resposta a adubação somente foi verificada no capim cortado mais rente ao solo.

Edvan et al. (2011) relatam que as características ecofisiológicas do capimbuffel e práticas de manejo baseadas em conceitos de características morfogênicas, características estruturais e acúmulo de forragem no pasto, são importantes para estabelecer o manejo adequado para essa gramínea nas regiões semiárida do Brasil. No caso do presente estudo, observa-se que a associação entre a adubação e rebaixamento do corte, permiti colher maior quantidade de forragem, como foi apresentado nos resultados de produção de matéria seca e matéria verde, que quando adubado com 20t/ha de esterco e cortado a $10 \mathrm{~cm}$ proporcionou uma maior produção, quando comparado ao corte a $20 \mathrm{~cm}$.

Para PMV e PMS por ciclos observouse efeito $(\mathrm{P}<0,05)$, com maior PMV concentrada no segundo ciclo, atingindo $4.086,63 \mathrm{~kg} / \mathrm{ha}$ (Figura 4). Os valores da PMV foram: Ciclo $1=544,77 \mathrm{~kg} / \mathrm{ha}$; Ciclo $2=4.086,63 \mathrm{~kg} / \mathrm{ha} ;$ Ciclo $3=$ $1.483,25 \mathrm{~kg} / \mathrm{ha}$; Ciclo $4=2.167 \mathrm{~kg} / \mathrm{ha}$.

$\mathrm{O}$ aumento da produção de matéria seca se deve, principalmente, aos minerais encontrados no adubo orgânico, como mostrou o estudo feito por Ceretta et al. (2003), onde praticamente todo o N, K e o $\mathrm{P}$, adicionado via esterco, estava em sua forma disponível às plantas, contribuindo assim de forma significativa para a produção de matéria seca das mesmas.

Estudo feito por Pontes et al. (2004) ressalta que a altura de corte consiste em uma das variações (intensidade e frequência de corte) que irão modificar a dinâmica de crescimento da pastagem, alterando os fluxos de biomassa, comprometendo assim a velocidade de rebrota. Dessa forma a fase inicial da rebrota é lenta até que um número suficiente de folhas tenha se expandido e passe a contribuir substancialmente para a fotossíntese da planta. 


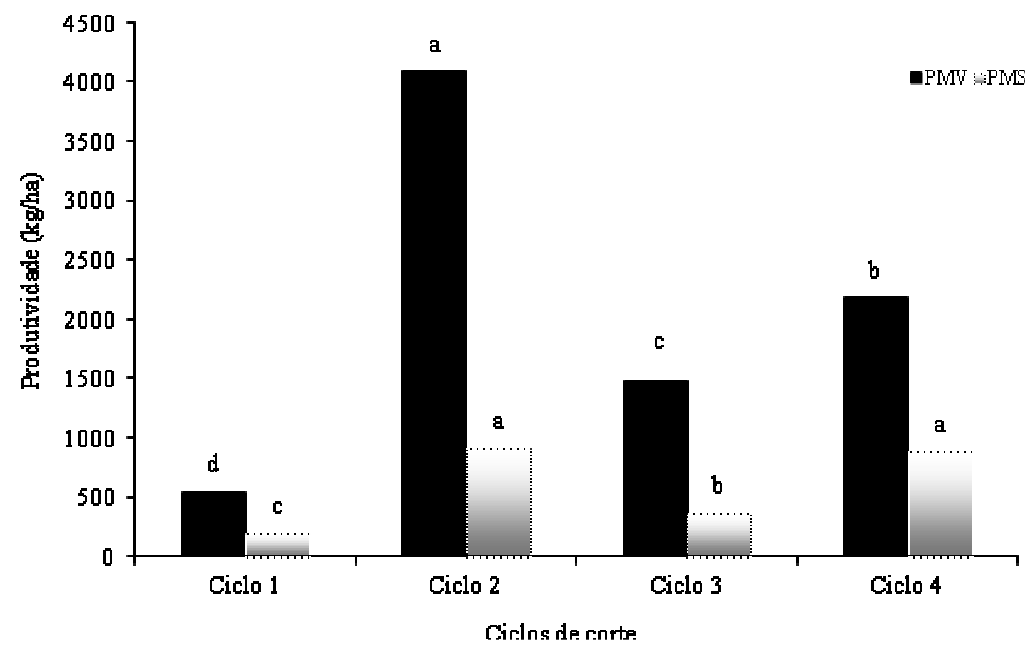

Médias seguidas de letras diferentes nas colunas de cada variável diferem entre si $(\mathrm{P}<0,05)$.

Figura 4. Produtividade de matéria verde (PMV), matéria seca (PMS), ao longo dos quatro ciclos do capim-buffel

Dantas Neto et al. (2000) mostraram que o máximo rendimento de matéria seca do capim-buffel estimado ocorreu com uma lâmina total aplicada de $334 \mathrm{~mm}$, atribuindo ao fato da disponibilização de nutrientes no solo por meio do aumento da umidade e, consequentemente, mineralização da matéria orgânica. Esse fato auxilia na explicação do aumento da produtividade no Ciclo 2, pela mineralização proporcionada pelas chuvas ocorridas durante o inicio deste ciclo, que em um só dia ocorreu uma chuva de cerca de $50 \mathrm{~mm}$, mais que o ocorrido durante o Ciclo1 inteiro.

Porém, a diminuição da produção de fitomassa no Ciclo 3 pode estar associado às baixas temperaturas do ar, que nos meses de junho e julho atingiram temperaturas mínima as 7 horas da manha de 19 e $18^{\circ} \mathrm{C}$, respectivamente, mas que podem ter sido bem mais baixas durante a madrugada, contribuindo para $\mathrm{o}$ comprometimento do crescimento do pasto. De acordo com Ludlow (1980) temperaturas abaixo de $20^{\circ} \mathrm{C}$ causam a diminuição substancial no crescimento de espécies forrageiras tropicais ocorrendo redução do crescimento, e o mesmo autor enquadra o capim-buffel como um capim de baixa resistência ao frio dentre os capins tropicais.

Vasconcelos et. al (2013) avaliando a produção do capim buffel adubado com digesta bovina verificou que a produção de fitomassa verde é influenciada pelas variáveis climáticas da região e pela disponibilidade de nutrientes, e quando estas variáveis são favoráveis, ou seja, precipitação bem distribuída durante todo o ciclo da planta e temperaturas acima de $20^{\circ} \mathrm{C}$, o desenvolvimento do capim obtêm as maiores produções, atingindo produções com mais de $1500 \mathrm{~kg} /$ ha de MS por ciclo.

Nas Figuras 5 e 6 observam-se efeito da interação $(\mathrm{P}<0,05)$ entre as doses de esterco e altura de resíduo no acúmulo de lâmina e colmo, respectivamente, não havendo diferenças $(\mathrm{P}>0,05)$ entre as duas alturas. Para o acúmulo total de colmo e de lâmina houve ajuste de modelo de forma linear crescente $(\mathrm{P}<0,05)$ com a utilização do adubo quando o capim foi colhido na altura de 
$10 \mathrm{~cm}$, não havendo ajustes de modelos de regressão quando o mesmo foi colhido a $20 \mathrm{~cm}$ para as duas variáveis. Quando o capim foi cortado a $10 \mathrm{~cm}$ provavelmente promoveu a renovação dos tecidos, favorecendo o efeito da rebrotação do capim e desta forma aumentando a taxa de aparecimento foliar e diminuição do alongamento de colmo.
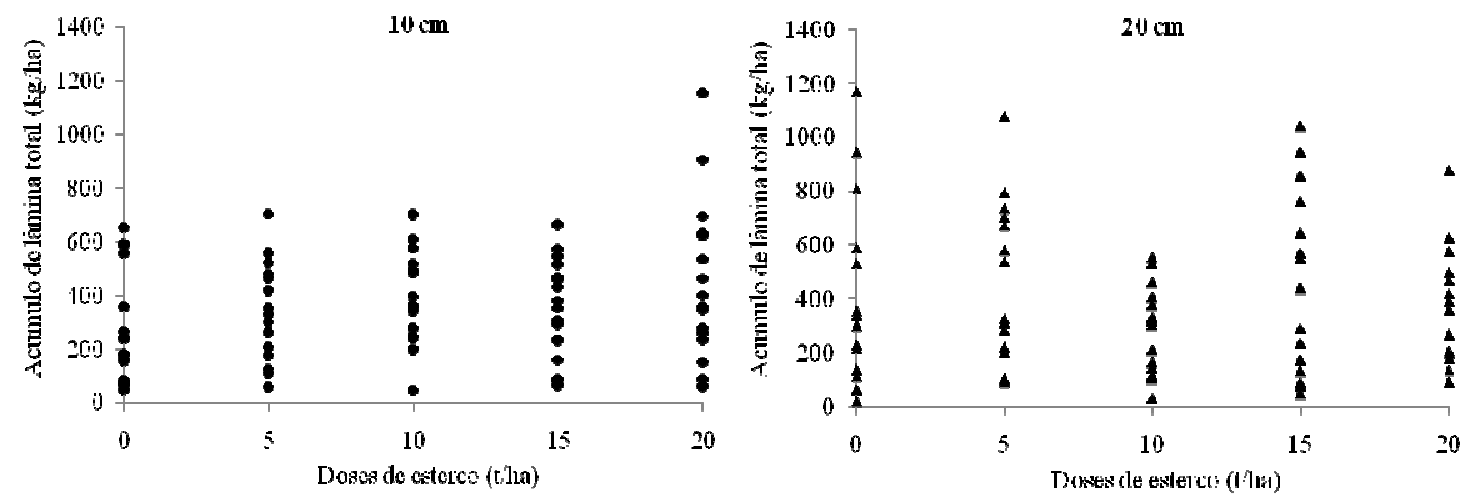

Figura 5. Acúmulos totais de matéria seca de lâmina do capim-buffel em função de alturas de resíduo e doses de esterco caprino

O efeito do esterco, principalmente o nitrogênio contido no mesmo, em alguns casos se expressa melhor quando a gramínea é colhida em uma altura de resíduo mais baixa, por meio da aceleração das taxas de aparecimento folhas e da densidade populacional de perfilhos (Figura 6). Provavelmente, o mesmo ocorreu com o capim-buffel, expressando sua resposta no aparecimento de folhas e aumentando sua densidade populacional.
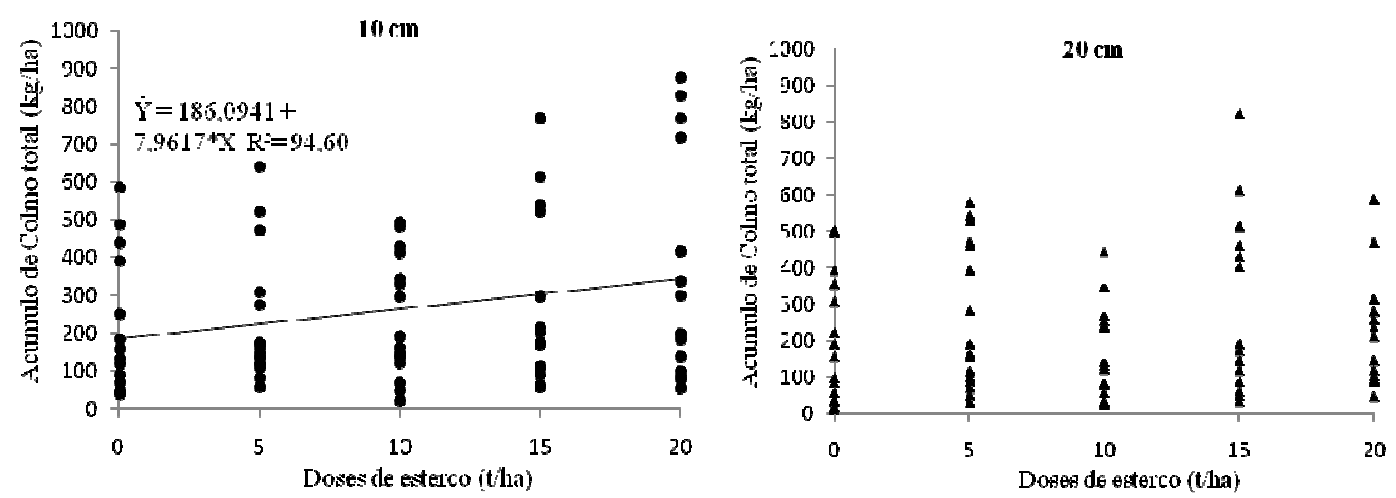

Figura 6. Acúmulos totais de matéria seca de colmo do capim-buffel em função de alturas de resíduo e doses de esterco caprino

Para produção por ciclos de acúmulo de lâmina e de colmo (Figura 7), observouse maior produção média concentrada no quarto ciclo com $579,5 \mathrm{Kg} / \mathrm{ha}$, porém este ciclo teve uma duração maior ( 80 dias) devido a paralisação do crescimento do capim ocorrida após o terceiro ciclo, evento que não era 
esperado, provavelmente sucedido pelas baixas temperaturas observadas nos meses de junho e julho, como relatado posteriormente, que mesmo tendo chovido $81 \mathrm{~mm}$ nesses dois meses não foi o suficiente para possibilitar $o$ crescimento. Contudo, o segundo ciclo com 40 dias atingiu 497,83kg/ha de acúmulo de lâmina e $481,28 \mathrm{~kg} / \mathrm{ha}$ de acúmulo de colmo devido às condições climáticas favoráveis, apresentando temperaturas mínimas acima de $21^{\circ} \mathrm{C}$ e pluviosidade de $144,2 \mathrm{~mm}$ durante todo o ciclo.

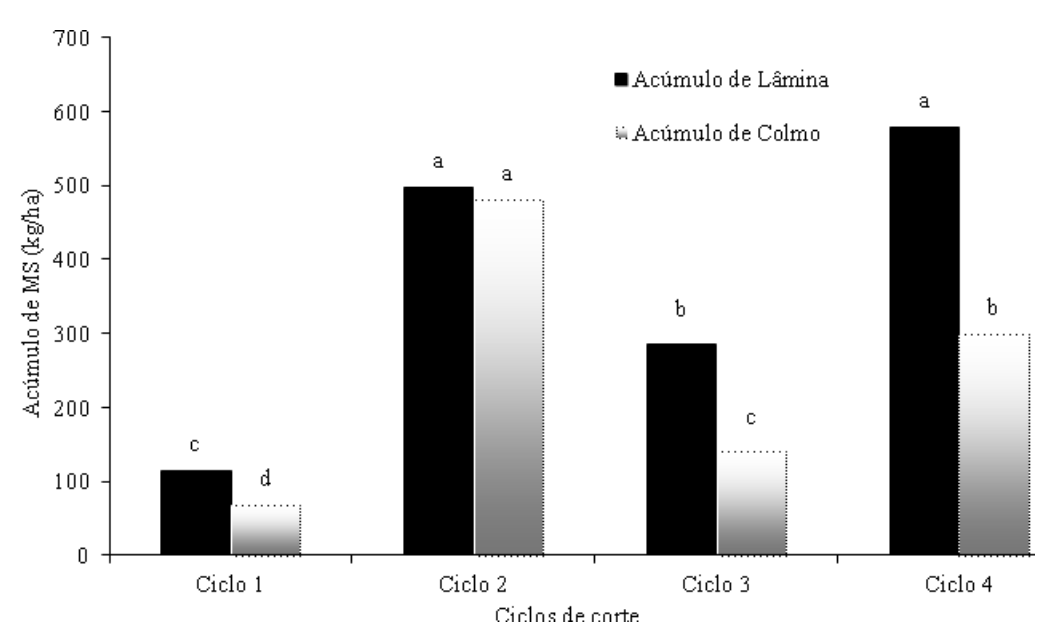

Médias seguidas de letras diferentes nas colunas de cada variável diferem entre si $(\mathrm{P}<0,05)$.

Figura 7. Acúmulo de matéria seca (MS) de lâmina e de colmo, nos quatro ciclos do capim-buffel

Analisando-se o acúmulo líquido Figura 8 , houve um efeito $(\mathrm{P}<0,05)$ de adubação e da época de corte, e da interação entre esses dois fatores, não havendo efeito $(\mathrm{P}>0,05)$ da altura de resíduo. Foi observado um aumento linear $(\mathrm{P}<0,05)$ do acúmulo líquido para a altura de $10 \mathrm{~cm}$ conforme o acréscimo das doses de adubo. Esses resultados implicam que a adubação não interferiu no processo de senescência do capimbuffel por meio do intervalo de corte pré-estabelecido.

O capim-buffel possui raízes profundas e bem desenvolvidas, aliadas à presença de rizomas que permitem o adiamento da desidratação e a manutenção do turgor devido a sua capacidade em explorar a água do solo. Esse conjunto de características pode explicar a elevada capacidade de rebrota do capim-buffel quando colhido com altura de resíduo de $10 \mathrm{~cm}$, principalmente associado à adubação.

Para o acúmulo líquido observado por ciclos (Figura 9), verificou-se maior produção média concentrada no segundo e no quarto ciclo, que no quarto ciclo foi ocasionada pelo período maior de dias e das reservas de carboidratos acumuladas e utilizadas pelo capim, devido às condições climáticas desfavoráveis ocorridas no final do terceiro ciclo e inicio do quarto ciclo.

Assim, a temperatura é uma das causas da flutuação estacional da produção de fitomassa. Por outro lado o segundo ciclo com 40 dias atingiu $937 \mathrm{~kg} / \mathrm{ha}$. 

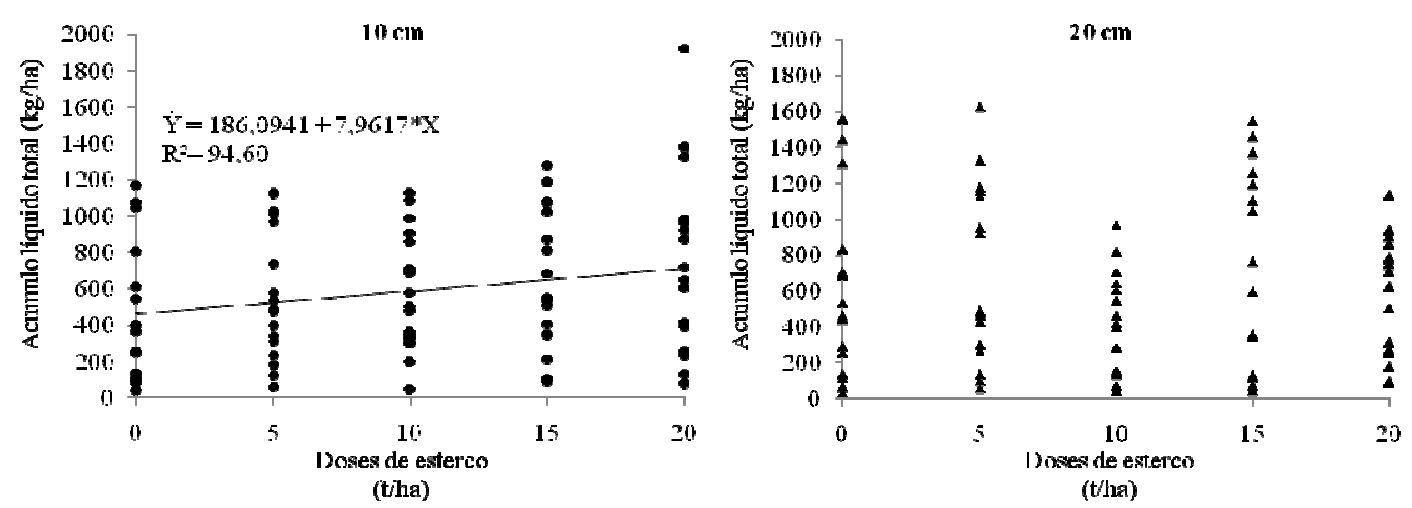

Figura 8. Acúmulo líquido do capim-buffel em função de alturas de resíduo e doses de esterco caprino

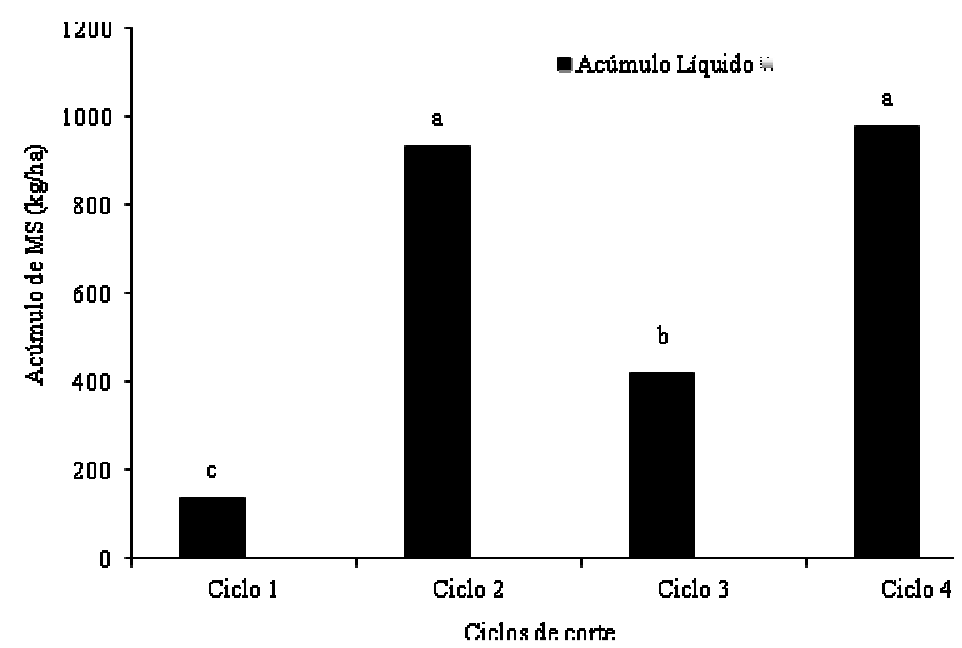

Médias seguidas de letras diferentes nas colunas de cada ciclo diferem entre si $(\mathrm{P}<0,05)$.

Figura 9. Acúmulo líquido de matéria seca (MS), ao longo dos quatro ciclos do capim-buffel

Em temperaturas abaixo de $20^{\circ} \mathrm{C}$ segundo um estudo feito por Jorge et. al (2008), para caracterizar uma coleção de capim-buffel, constatou-se que durante os meses mais frios, os grupos ambientais apresentaram temperaturas baixas, todos abaixo de $20^{\circ} \mathrm{C}$, e em alguns acessos abaixo de $10^{\circ} \mathrm{C}$, desta forma obtendo as menores produções do ano, com menores folhas e colmos mais finos, e em alguns casos até paralisando o seu crescimento, corroborando com a presente pesquisa, que apresentou diminuição da produtividade com o decréscimo das temperaturas, como ocorreu no terceiro ciclo que foi menor que $500 \mathrm{~kg} / \mathrm{ha}$ de $\mathrm{MS}$, demonstrando a susceptibilidade dessa gramínea a temperaturas a baixo de $20^{\circ} \mathrm{C}$.

A adubação orgânica eleva a produção de fitomassa do capim buffel quando associada à altura de corte de $10 \mathrm{~cm}$, permitindo melhor aproveitamento da massa de forragem produzida. 
Rev. Bras. Saúde Prod. Anim., Salvador, v.14, n.3, p.587-598 jul./set., 2013 http://www.rbspa.ufba.br ISSN 15199940

\section{REFERÊNCIAS}

CERETTA, C.A.; DURIGON, R.; BASSO, C.J.; BARCELLOS, L.A.R.; VIEIRA, F.C.B. Características químicas de solo sob aplicação de esterco líquido de suínos em pastagem natural. Pesquisa agropecuária brasileira, v.38, n.6, p.729-735, 2003.

DANTAS NETO, J.; SILVA, F.A.S.; FURTADO, D.A.; MATOS, J.A. Influência da precipitação e idade da planta na produção e composição química do capim-buffel. Pesquisa Agropecuária Brasileira, v.35, n.9, p.1867-1874, 2000.

EDVAN, R.L.; SANTOS, E.M.; SILVA, D.S.; ANDRADE, A.P.; COSTA, R.G.; VASCONCELOS, W.A. Características de produção do capimbuffel Submetido a intensidades e freqüências de corte. Revista Archivos de Zootecnia, v.60, n.232, p.12811289, 2011.

FERREIRA, D.F. Sisvar: um programa para análises e ensino de estatística.

Revista symposium, v.6, p.36-41, 2008 .

JORGE, M.A.B.; WOUW, M.V.; HANSON, J.; MOHAMMED, J. Characterisation of a collection of buffel grass (Cenchrus ciliaris).

Tropical Grasslands, v.42, p.27-39, 2008.

LUDLOW, M.M. Stress physiology of tropical pasture plants. Tropical

Grassland, v.14, n.3, p.136-145, 1980.

MARCELINO, K.R.A.;

NASCIMENTO JR, D.; SILVA, S.C.; EUCLIDES, V.P.B.; FONSECA, D.M.

Características morfogênicas e estruturais e produção de forragem do capim-marandu submetido a intensidades e freqüências de desfolhação. Revista Brasileira de Zootecnia, v.35, n.6, p.2243-2252, 2006.

MELO, R.F.; BRITO, L.T.L.; ANJOS, J.B.; PEREIRA, L.A. Avaliação do uso de adubo orgânico nas culturas de milho e feijão-caupi em barragem subterrânea. Revista Brasileira de Agroecologia, v.4, n.2, p.1264-1267, 2009.

MENEZES, R.S.C.; SALCEDO. I.H. Mineralização de $\mathrm{N}$ após incorporação de adubos orgânicos em um Neossolo Regolítico cultivado com milho.

Revista Brasileira de Engenharia Agrícola e Ambiental, v.11, p.361-367, 2007.

NAGANO, N.R.; ZANET, C.; TIRITAN, C.S.; SANTOS, D.H. Efeito da adubação nitrogenada e altura de corte sobre o capim Tanzânia. Revista Scientia Agraria Paranaenis, v.10, n.1, p.100-112, 2011.

PONTES, L.S.; CARVALHO, P.C.F.; NABINGER, C.; SOARES, A.B. Fluxo de biomassa em pastagem de azevém anual (Lolium multiflorum Lam.) manejada em diferentes alturas. Revista Brasileira de Zootecnia, v.33, n.3, p.529-537, 2004.

\section{SILVA, S.C.; NASCIMENTO} JUNIOR, D. Avanços na pesquisa com plantas forrageiras tropicais em pastagens: características morfosiológicas e manejo do pastejo. Revista Brasileira de Zootecnia, v.36, p.121-138, 2007.

SILVA, T.O.; MENEZES, R.S.C.; TIESSEN, H.; SAMPAIO, E.V.S.B.; SALCEDO, I.H.; SILVEIRA, L.M. Adubação orgânica da batata com esterco e/ou Crotalaria juncea. I - 
Produtividade vegetal e estoque de nutrientes no solo em longo prazo.

Revista Brasileira de Ciência do Solo, v.31, p.39-49, 2007.

VASCONCELOS, W.A.D.;

ANDRADE, A.P.D.; SANTOS, E.M.;

EDVAN, R.L.; SILVA, D.S.; SILVA,

T.C. Características morfogenéticas e produção do capim buffel adubado com digesta bovina sólida. Revista

Brasileira de Saúde e Produção

Animal [online], v.14, n.1, p.01-09, 2013.

Data de recebimento: 15/04/2013

Data de aprovação: 27/09/2013 